\title{
Evaluation of Symmetric C-PVT Solar Collector Designs with Vertical Bifacial Receivers
}

\author{
Rajan Panchal', João Gomes², Diogo Cabral ${ }^{2}$, Abideme Eleyele ${ }^{3}$, Miguel Lança ${ }^{4}$ \\ ${ }^{1}$ University of Kassel, (Germany) \\ ${ }^{2}$ University of Gävle (Sweden) \\ ${ }^{3}$ Uppsala University (Sweden) \\ ${ }^{4}$ Instituto Superior Técnico, Lisboa (Portugal)
}

\begin{abstract}
Photovoltaic thermal (PVT) solar collectors can be an effective solution for system output improvement. Photovoltaic thermal collectors naturally have a more expensive receiver than simpler photovoltaic or thermal only collectors, therefore making concentration a more appealing solution to achieve cost reduction. However, concentrating systems need careful analysis on the design phase in order to optimize the annual output. In addition, for stationary (non-tracking) collectors, it is critical to determine the incidence angle modifier (IAM). For this reason, a reflector study was carried out to determine suitable reflector designs for a stationary concentrating PVT collector. The reflectors were simulated using a Monte Carlo raytracing software called Tonatiuh. The two selected reflectors designs were named "pure parabola" (PP) and "compound parabolic concentrator" (CPC). The concentration ratio of 1.2 and 1.6 were selected for each reflector designs, which means a total of 4 collector troughs. The next step involved the construction of the two selected C-PVT collector designs, which were built and subsequently tested by the authors. The IAM was assessed and discussed by simulation and outdoor testing in detail.

The IAM results show similar decreases in longitudinal IAM for both the PP and the CPC CPVT collector for the 1.2 concentration factor. For the transversal IAM with 1.2 of concentration factor, the CPC over performs. For the 1.6 concentration prototype collectors, the results are fairly similar. Lastly, the annual output was also simulated and presented.
\end{abstract}

Keywords: CPVT, CPC, PP, Bifacial Receiver, IAM, Collector Testing, Ray Tracing

\begin{tabular}{|l|c|c|}
\hline \multicolumn{1}{|c|}{ Technical Term } & Symbol/Abbreviation & Unit \\
\hline Photovoltaic Thermal & $P V T$ & - \\
Concentrating Photovoltaic Thermal & $C P V T$ & - \\
Pure Parabola & $P P$ & - \\
Compound Parabolic Concentrator & $C P C$ & - \\
Computer-Aided Design & $C A D$ & Adimensional \\
Incidence Angle Modifier & $I A M$ & Adimensional \\
Incidence Angle Modifier - Longitudinal & $I A M L$ & Adimensional \\
Incidence Angle Modifier - Transversal & $I A M T$ & Adimensional \\
\hline
\end{tabular}

\section{Introduction}

Easy access to energy has played a major role in the economic growth of the world's nations and the uplifting of the life standards of the world. Several factors such as increasing urbanization, technological growth and human population have led to a massive increase in the energy demand in the world. Today, in the so-called developed countries, the energy consumption is increasing at a rate of $1 \%$ per year while for the developing countries, the rate is $5 \%$ per year (IRENA, 2017). Solar energy is considered one of the most important renewable energy sources since it is inexhaustible and carbon-free. Over the past 15 years, a steep drop in the levelized cost of electricity for Solar photovoltaics (PV) has occurred, as the average levelized cost of PV in 2017 is 0.10 USD/kWh. These costs are lower than the upper-end price of fossil fuel power plant (Al-Najiden et al. 2017). Two main options for making PV systems even a further affordable solution stand out: 1) increase the efficiency of PV cells 2) decrease the total investment cost of the system. The use of concentrators to focus the light on PV cells is a possible path, as it increases the total output from each solar cells while decreases the cost per $\mathrm{m}^{2}$ of collector.

The aim of this study is to compare the performance of two concentrating photovoltaic thermal (CPVT) 
collectors. These CPVT collectors are using the same receiver and two different reflector geometries: compound parabolic collector concentrator (CPC) and pure parabola (PP). Two different concentration ratios were utilized.

\subsection{Pure Parabola (PP)}

In concentrating systems, a trade-off between system efficiency and cost reduction must be found (Jafrancesco et al. 2012), which always involves truncation of the reflector before reaching the maximum theoretical concentration.

Concentrators consist mainly of two groups when considering the concentrator surface: $2 \mathrm{D}$ and 3D collectors. An example of the 2D collector is the parabolic trough collector that uses a PP reflector geometry design. A know example of a 3D concentrator is the parabolic dish. 3D concentrators have a significantly higher concentration potential (Nilson, 2005).

\subsection{Compound Parabolic Concentrators (CPC)}

Another example of a 2-D concentrator is the compound parabolic concentrator. All CPC collectors are nonimaging collectors. CPC collectors are usually a combination of two identical parabola and circle. Example of $\mathrm{CPC}$ collector is shown in figure 1. Point $\mathrm{C}$ to $\mathrm{A}$ and point $\mathrm{D}$ to $\mathrm{B}$ shows two tilted parabolas. $\mathrm{F} 1$ is a focus point of parabola $\mathrm{CA}$, and $\mathrm{F} 2$ is a focus point of parabola $\mathrm{DB}$. $\mathrm{AB}$ is circular arc tangent to both parabolas on each side. When the incident rays on the aperture plane are parallel to the axis of parabola 1 , they will be reflected and focused at point F1. It is the same for incident rays parallel to the optical axis of parabola 2, which will end up on point F2.

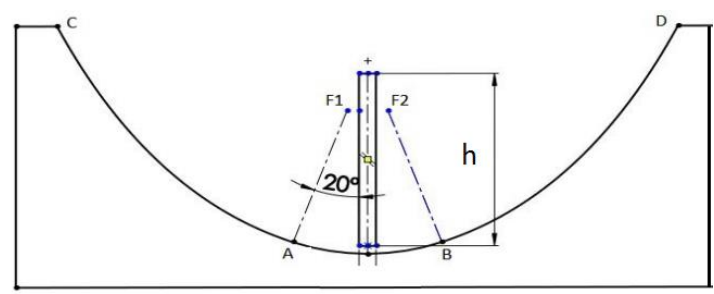

Fig. 1: Geometry of a compound parabolic reflector. $h$ stands for collector height.

\subsection{Concentrating Photovoltaic-Thermal Collectors}

PVT collectors generate electricity and heat from the same area. PVT collectors generally have a higher $\mathrm{m}^{2} \operatorname{cost}$ but also a higher annual output. The receiver is always the expensive elements of any collector. Concentrating PVT (CPVT) collectors concentrate to reduce cost. The increased receiver cost of PVT's, when compared to standard PV or thermal collectors further increases the benefit of concentration. However, increasing the amount of radiation on the solar cells corresponds to an increase in the current generated, which leads to higher resistance losses (Sharaf and Orhan, 2015). Additionally, the stagnation temperature of the collector also raises, which can imply that the materials must be more expensive in order to cope with the increased temperatures.

Silicon solar cells are the most common in the market today and have reduced efficiency at higher temperature. Generally, the performance temperature coefficient is around $0.4 \% / \mathrm{K}$. Increased radiation from concentration raises the temperature of solar cells, if no cooling system is in place. In PVT collectors, water (or mixture of water and glycol) is often used to carry the excess heat generated out of PV cells. In PVT collectors, the heat that would otherwise be reducing the efficiency of the PV cells is turned into valuable energy (Kramer and Helmers, 2013; Good, 2016).

\section{Method}

The method utilized for this paper can be summarized in the following three steps, such as a) Ray tracing simulations in Tonatiuh; b) Construction of the selected collectors design; and c) outdoor testing of the constructed collectors.

\subsection{Incidence Angle Modifier (IAM)}

The main test performed on the collector was the Incidence Angle Modifier. This is a key parameter on stationary 


\section{C-PVT collectors.}

Incidence angle is the angle between the incoming solar rays and optical axis of the collector. The IAM of any solar collector shows the variance in output performance of a collector as the angle of incoming rays changes with respect to the normal of the collector. The IAM comprises the incidence angle dependencies of the collector's optical efficiency (Duffie and Beckman, 2013). It is defined as the ratio of the optical efficiency at an angle of normal incidence to the optical efficiency at an arbitrary angle of incidence (Stine and Harrigan, 1986). It is fundamental to quantify a stationary concentrating collector's IAM in order to be able to predict the difference in output of the collector. Incidence angle further can be divided on to two planes: Transversal and Longitudinal.

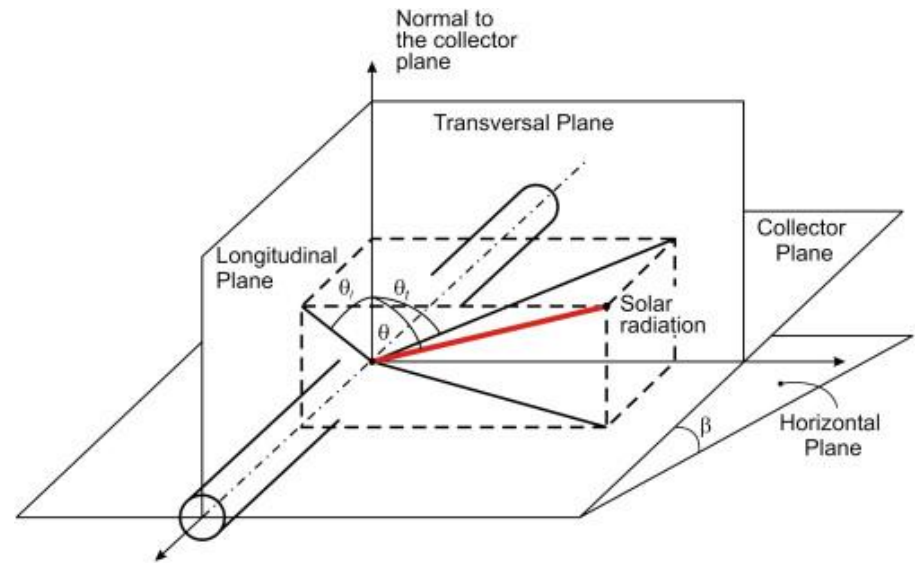

Fig. 2: Transversal and Longitudinal IAMs.

Collectors are measured in order to obtain their transversal and longitudinal IAM. For flat plate collectors, transversal and longitudinal IAM profiles follow the profile, which is generally similar cosine curve. For any concentrating collector, transversal and longitudinal IAM profiles are not the same. Longitudinal IAMs are measured keeping collector tilt equal to $90^{\circ}$ - solar altitude angle while changing surface azimuth angle with respect to solar azimuth angle. For measuring the transversal IAMs, you keep constant the longitudinal plane while varying the transversal. The IAMs can be described mathematically using the below equations.

Overall collector efficiency $\left(\operatorname{Eff}\left(\theta_{i}\right)\right)=\frac{\operatorname{Power}\left(\theta_{i}\right)[W]}{I\left[W / m^{2}\right] \times A_{a p}\left[m^{2}\right]}$

The optical efficiency $(\eta(\theta))=\max \left(E f f\left(\theta_{i}\right)\right)$

Therefore, the transversal and longitudinal IAM at different $\theta$ is evaluated using (eq. 3 ).

$\operatorname{IAM}\left(\theta_{i}\right)=\frac{\eta(\theta)}{\eta\left(0^{0}\right)}$

Where $\mathrm{I}$ is the Irradiance, $A_{a p}$ is the aperture area and $\eta\left(0^{\circ}\right)$ is the efficiency at $0^{\circ}$ incidence angle (normal to the collector).

\subsection{Ray tracing simulation}

Tonatiuh is a Monte Carlo ray tracing software using $\mathrm{C}++$ language that was developed by CENER. Tonatiuh is validated by outdoor test data from different concentrated solar applications. The simulation in a system is carried on three levels: Interaction between the concentrating system and radiation elements, concentrating system model, and incoming solar radiation (Blanco et al. 2009).

The software allows input of computer aided drawings (CAD) files, which is useful to design complex and precise reflector geometries. For this paper, all reflector geometries are imported as CAD file Tonatiuh. The next step is defining the material properties of all components of the collector: glass, receiver, reflector and side gables are defined for their reflectivity, transmissivity, and absorptivity. Tonatiuh simulations deal only with direct radiation. Solar pillbox option is selected to have the same solar intensity at any point on sun's disc.

The software does not take weather conditions into consideration. Irradiation from the sun is set to at $1000 \mathrm{~W} / \mathrm{m}^{2}$. Ten thousand solar rays are randomly created, and directed to the collector area. For the simulation of the transversal and longitudinal incidence angle modifier (IAM) values are taken at every $5^{\circ}$. 


\subsection{Outdoor Testing}

The solar testing rig is located on the roof of the University of Gävle in Sweden, situated at latitude: N 6040'6.77"; longitude: E $17^{\circ} 6{ }^{\prime} 58.95^{\prime \prime}$.

The test rig maintains a steady flow and inlet temperature to the C-PVT collectors. The test rig is also able to measure the solar radiation (total and diffuse), the inlet and outlet temperature in the collectors, the ambient temperature, the properties of the IV curve. The test rig is able to measure two PVT collectors simultaneously. Two pyranometers are placed on the same plane as the collector, global and diffuse irradiance at the collector plane. Kipp \& Zonen pyranometers are utilized CMP6 and CMP3. The IV tracer applies a load and measures current and voltage. The resolution of the IV tracer is of $0.008 \mathrm{~V}$ and $0.002 \mathrm{~A}$. The test rig has $4 \mathrm{PT} 1000$ for the inlet and outlet temperature and an additional one for ambient temperature. Flow is also recorded is scientific grade equipment. A CR1000 data logger from Campbell Scientific is used to record all the data.

A stand was built to hold the collector during testing. This stand was made to be able to rotate and thus facilitate the IAM testing. The supporting structure is made of metal, and a revolving frame made of wood. A 2D movement of the structure supported the authors in tracking the sun altitude and azimuth.

\subsection{Design of the reflector geometry}

Two reflector geometries were designed for the test prototypes: CPC and PP. For both CPC and PP geometries two different were created with $\mathrm{C}=1.2$ and $\mathrm{C}=1.6$, where $\mathrm{C}$ is the concentration factors which can be calculated using equation 4.

Concentration ratio $(\mathrm{C})=\frac{\text { Total aperture area }}{\text { Total receiver area }(2 \times \text { receiver length } \mathrm{x} \text { receiver width })}$

Figure 3 and 4 show how the reflections take place in parabolic and circular geometries from three different angles. The parabola is symmetrical along the receiver plane, the "axis of symmetry" (Adsten et al. 2005).

(a)

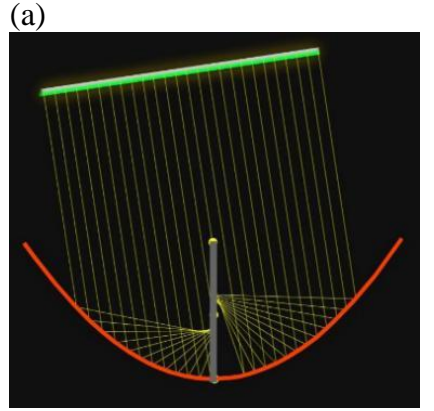

(b)

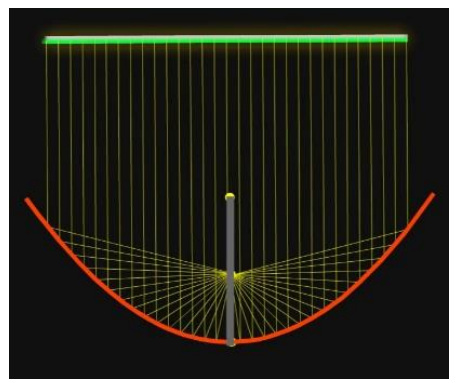

(c)

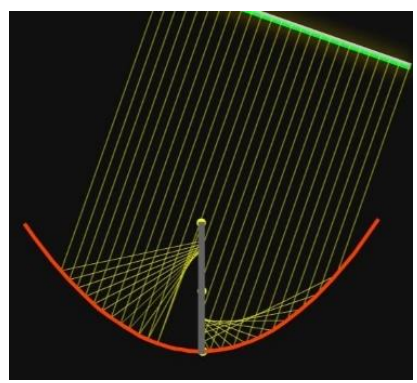

Fig. 3: Reflection of rays at different angle from parabolic reflector

According to (b) of figure 3 if incoming rays are parallel to the optical axis of parabola, all rays focus on focus point of the parabola. This makes the line of focused points along the receiver length and has the highest intensity of radiation. Rays coming inside the parabolic reflector at a different angle and their reflection behaviour from the parabolic reflector is as shown in (a) and (c). The focus of the collector slides upwards or downwards and scatters on an optical axis with respect to the incident rays on the collector aperture.

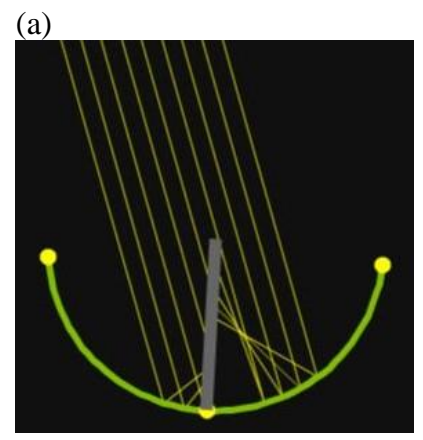

(b)

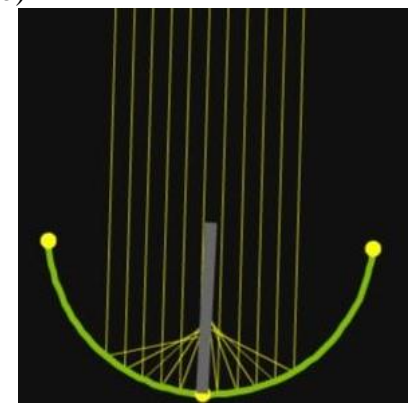

(c)

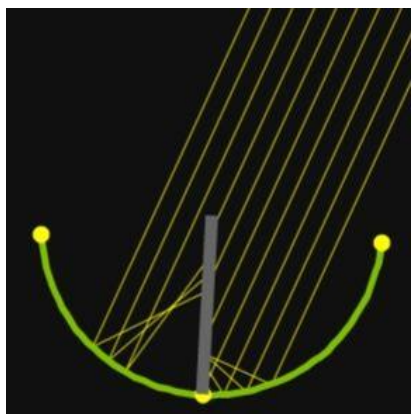

Fig. 4: Reflection of rays at different angle from circular arc reflector 
Compound Parabolic Concentrator design in this study is composed of circle and parabola. From (b) of figure 4 when the incoming rays are parallel to the axis of the circle, all rays focus on the focus point. (b) and (c) also evidently shows the circular part tends to focus all incoming rays on the its focal point in such a way that no matter from which angle rays are coming from, it will be reflected on the receiver of the collector

\subsubsection{Parabolic concentrator design}

The figure below shows one of the ribs that give the reflector shape. These ribs are used as an integral part of the collector box. This rib features a PP geometry with two different concentration factors. Focus length of PP 1.2 is $44.96 \mathrm{~mm}$ and PP 1.6 is $79.93 \mathrm{~mm}$. Depth of concentrators is $218 \mathrm{~mm}$.

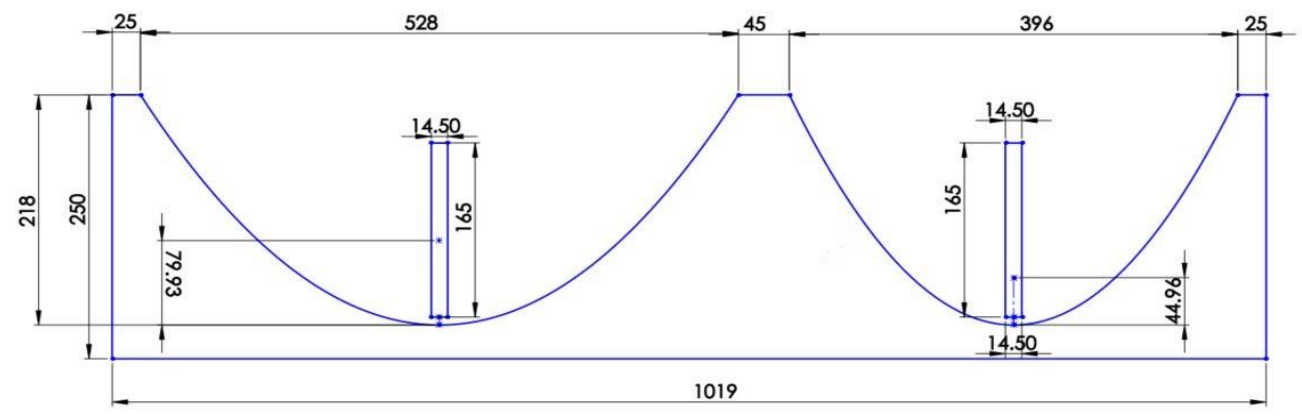

Fig. 5: Rib design PP 1.2 (right) and PP 1.6 (left)

Tab. 1: PP design Specifications

\begin{tabular}{|c|c|c|}
\hline Properties & PP 1.2 & PP 1.6 \\
\hline Aperture width & $396 \mathrm{~mm}$ & $528 \mathrm{~mm}$ \\
\hline Aperture length & $2321 \mathrm{~mm}$ & $2321 \mathrm{~mm}$ \\
\hline Total aperture area & $919116 \mathrm{~mm}^{2}$ & $1225488 \mathrm{~mm}^{2}$ \\
\hline Receiver width & $165 \mathrm{~mm}$ & $165 \mathrm{~mm}$ \\
\hline Receiver length & $2321 \mathrm{~mm}$ & $2321 \mathrm{~mm}$ \\
\hline Total receiver area & $765930 \mathrm{~mm}^{2}$ & $765930 \mathrm{~mm}^{2}$ \\
\hline
\end{tabular}

\subsubsection{CPC concentrator design}

Figure displays the design of the ribs with two different concentration factors for CPC reflector design. The CPC design is composed of circular and parabolic parts. The circular arc in the middle and two parabolas is tangent to circular arc, tilted at specific angle towards each other. F1 and F2 are focus points of parabola CA and DB. $\mathrm{F} 3$ and F4 are focus points of parabola GE and HF. Circular arc of CPC 1.6 is $40^{\circ}$ and CPC 1.2 is $60^{\circ}$. Acceptance half angle of CPC 1.6 is little more than $20^{\circ}$, and acceptance half angle of CPC 1.2 is little more than $30^{\circ}$ because of the position of the focus point on the receiver and lower truncation height of parabola.

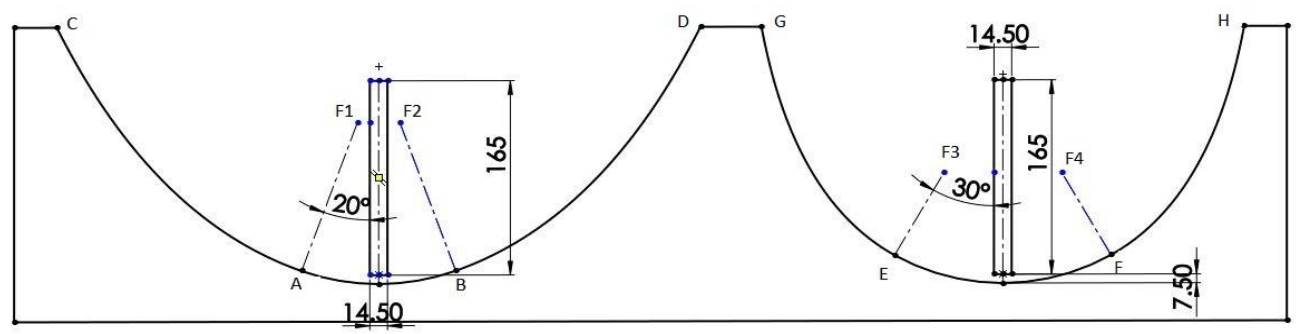

Fig. 6: Rib design CPC 1.2 (right) and CPC 1.6 (left) 
Tab. 2: CPC design Specifications

\begin{tabular}{|c|c|c|}
\hline Properties & CPC 1.2 & CPC 1.6 \\
\hline Aperture width & $396 \mathrm{~mm}$ & $528 \mathrm{~mm}$ \\
\hline Aperture length & $2321 \mathrm{~mm}$ & $2321 \mathrm{~mm}$ \\
\hline Total aperture area & $919116 \mathrm{~mm}^{2}$ & $1225488 \mathrm{~mm}^{2}$ \\
\hline Receiver width & $165 \mathrm{~mm}$ & $165 \mathrm{~mm}$ \\
\hline Receiver length & $2321 \mathrm{~mm}$ & $2321 \mathrm{~mm}$ \\
\hline Total receiver area & $765930 \mathrm{~mm}^{2}$ & $765930 \mathrm{~mm}^{2}$ \\
\hline Circular Arc & $60^{0}$ & $40^{0}$ \\
\hline Radius of circle & $184.92 \mathrm{~mm}$ & $177.56 \mathrm{~mm}$ \\
\hline
\end{tabular}

\subsection{Collector prototype construction process}

The construction process involved the implementation of the main elements of collectors, which are the ribs, reflector, glass, gables and receiver. Great care has been taken to ensure that the reflector shape is built precisely according to design. The following figures below shows the different step of construction process:

1) Ribs: Thickness and height of all ribs used in the construction of collector are $18 \mathrm{~mm}$ and $250 \mathrm{~mm}$
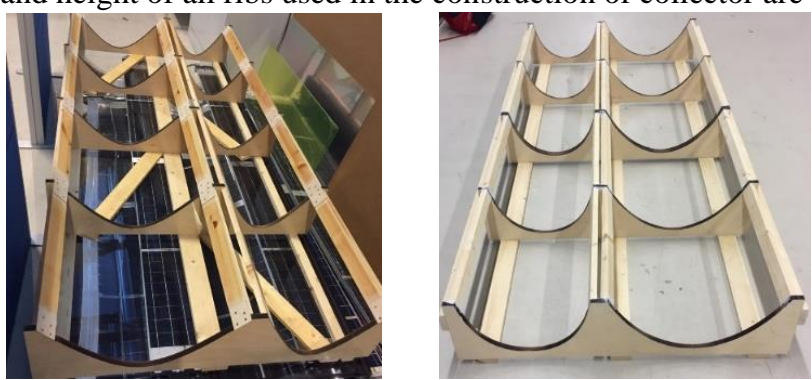

Fig. 7: Rib design CPC (right) and CPC (left)

2) Reflector: Reflector sheet used is from Alanod with a total reflectance of $92 \%$. Reflector thickness is $0.4 \mathrm{~mm}$.

3) Glass: The solar glass sits on the top of the ribs. The glass has anti-reflective treatment on the both sides of solar glass. Glass cover is made of low iron glass with a $95 \%$ solar transmittance.
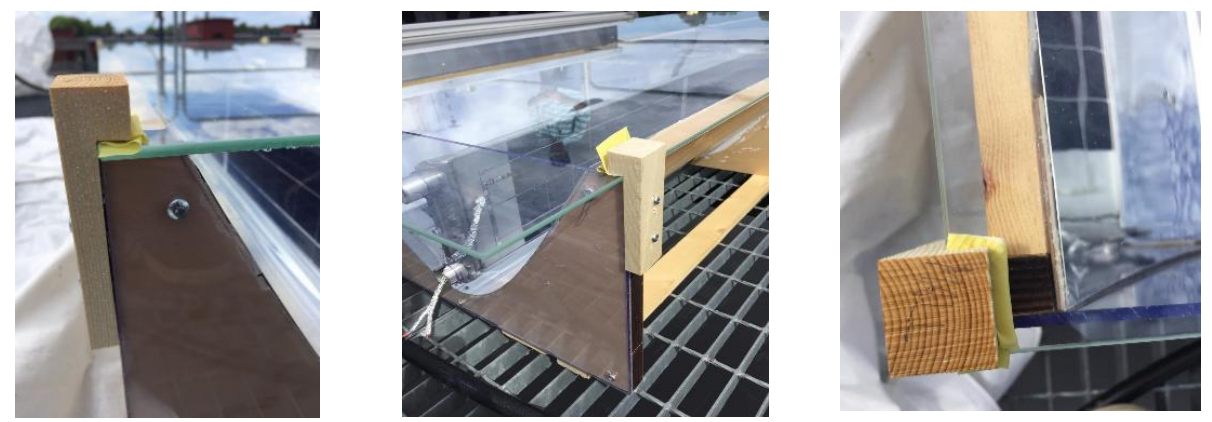

Fig. 8: Anti-reflective treated glass attached to the ribs

4) Gables: The plastic side gable has $90 \%$ transparency. Gables on both ends of the collector holds the receiver firmly. The gables also supports the weight of the piping system on both ends of a collector.

5) Receiver: The receiver is a standard bifacial PVT that has been donated by Solarus Sunpower. The receiver rests on the gables at both ends of the collector and on a special support in the center. Firm support for the receiver is ensured to prevent any bending while tilting the collector. The receiver is made of aluminum due to its ability to provide a good structural support to the collector, low cost and excellent heat conductive ability. The receiver features eight elliptical channels, which for the heat transfer fluid to flow. A manifold on both ends allows connecting the bushings and pipes. Each receiver side has four cell strings. These cells strings are connected in a series and each string has a bypass diode 
for minimizing the performance reduction from shading. The edge strings have eight cells each while the center strings have 11 cells. In total, each receiver has eight cell strings (four on each side: top and bottom). Bottom and top cell strings are connected separately, therefore concentration differences on individual sides do not result in power loss.

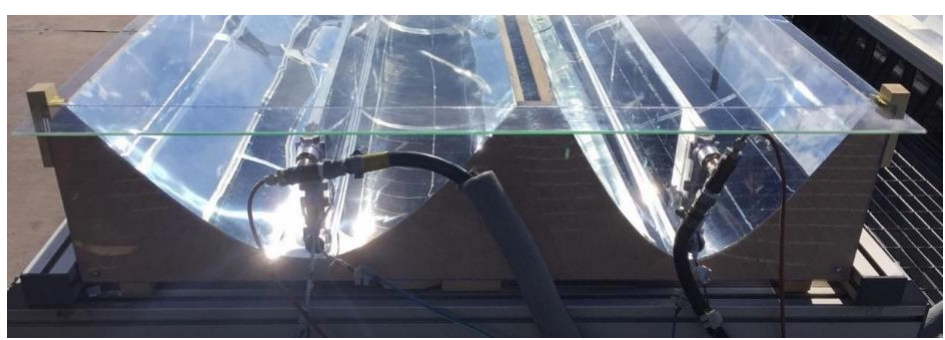

Fig. 9: Side gables of the collector

\section{Results}

\subsection{Simulations Results}

The simulation results of the IAM are shown below. For both PP and CPC reflector geometries with a concentration 1.2:

Analyzing the results, it is possible to note that the simulated longitudinal IAM do not differ much, although after $40^{\circ}$, the CPC is slightly over-performing. For the transversal IAM, the results show a significant overperformance of the CPC when compared to the PP, which starts directly at $10^{\circ}$ and increases as incidence angle increases.
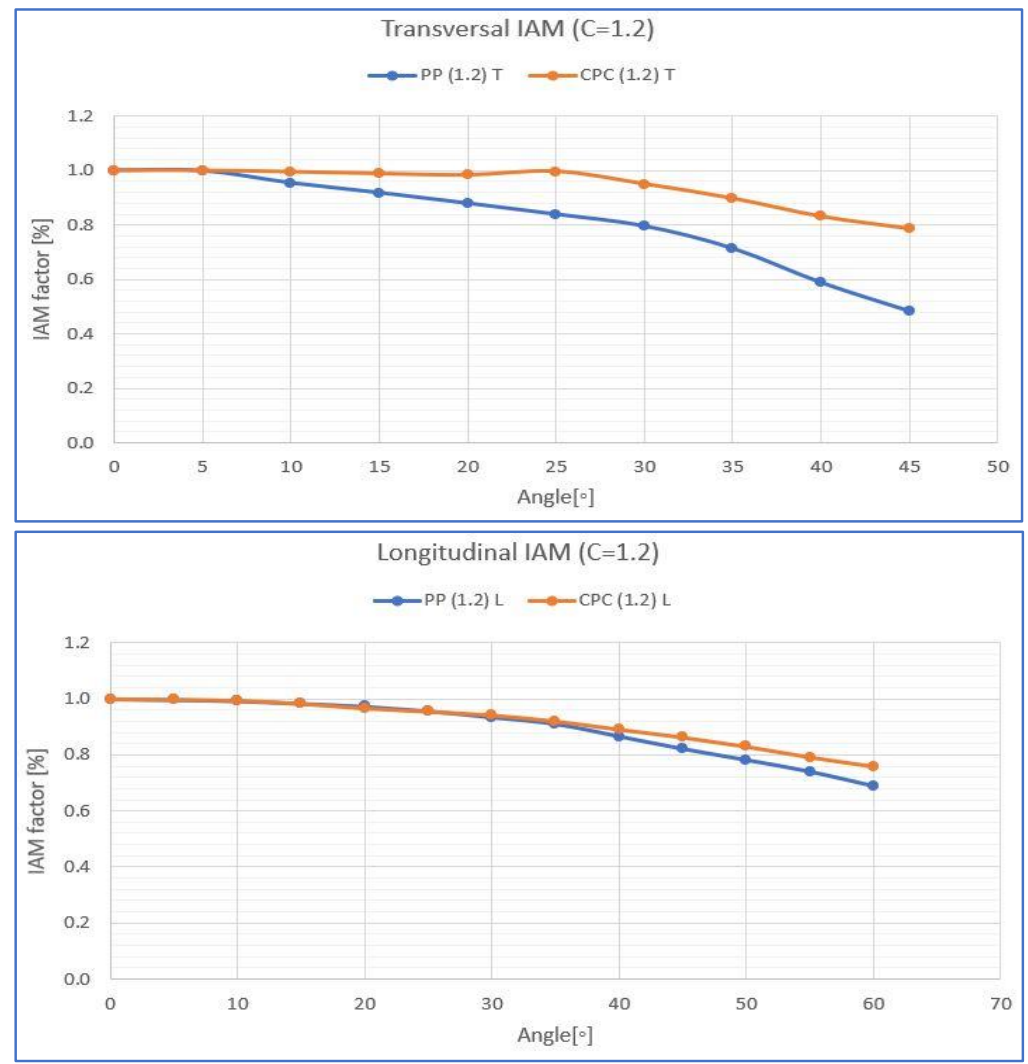

Fig. 10: Longitudinal (bottom) and Transversal (top) IAMs simulation result at C=1.2.

For both PP and CPC reflector geometries with a concentration 1.2: 

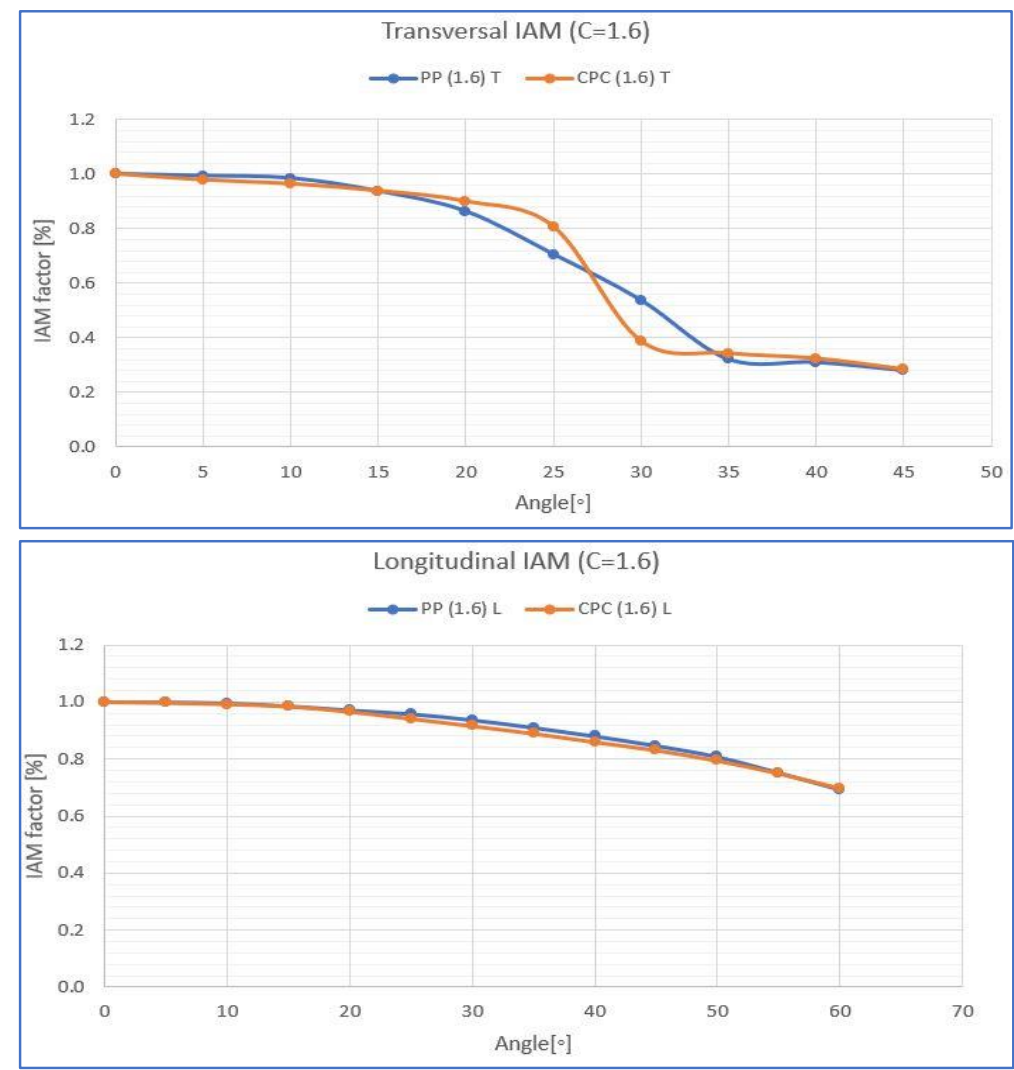

Fig. 11: Longitudinal (bottom) and Transversal (top) IAMs simulation result with $\mathrm{C}=1.6$.

Analyzing the results, it is possible to note that the simulated IAM longitudinal of the PP and the CPC match almost perfectly for the 1.6 concentration factor. However, the same is not true for the transversal IAM, which maintains a higher performance at $20^{\circ}$ and $25^{\circ}$ but a lower performance at $30^{\circ}$. For the remaining points, the curves are rather similar.

When comparing the two PP designs and the two CPC designs between themselves, it is obvious that the lower concentration outperforms the higher concentrations, as expected. This effect is more visible on the transversal IAM.

\subsection{Outdoor Measurement Results and Simulated Results}

The following figures compare the IAM measured and tested for both the CPC and the PP

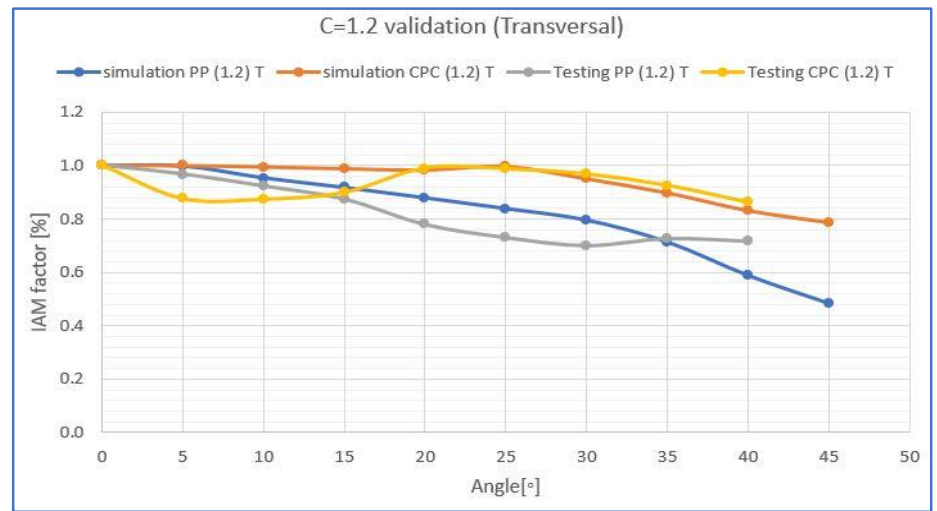




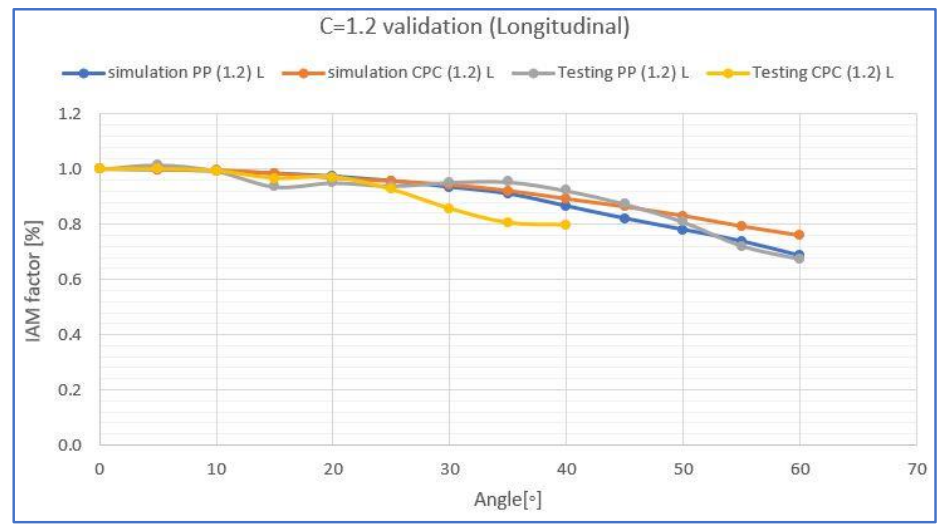

Fig. 12: Longitudinal (bottom) and Transversal (top) IAMs simulation result with $\mathrm{C}=1.2$.

The longitudinal simulated and measured IAM curves are fairly similar, as intended. This happens for both the PP and the CPC. However, for the transversal IAM, the differences are more substantial, potentially due to measurement errors on the outdoor testing.
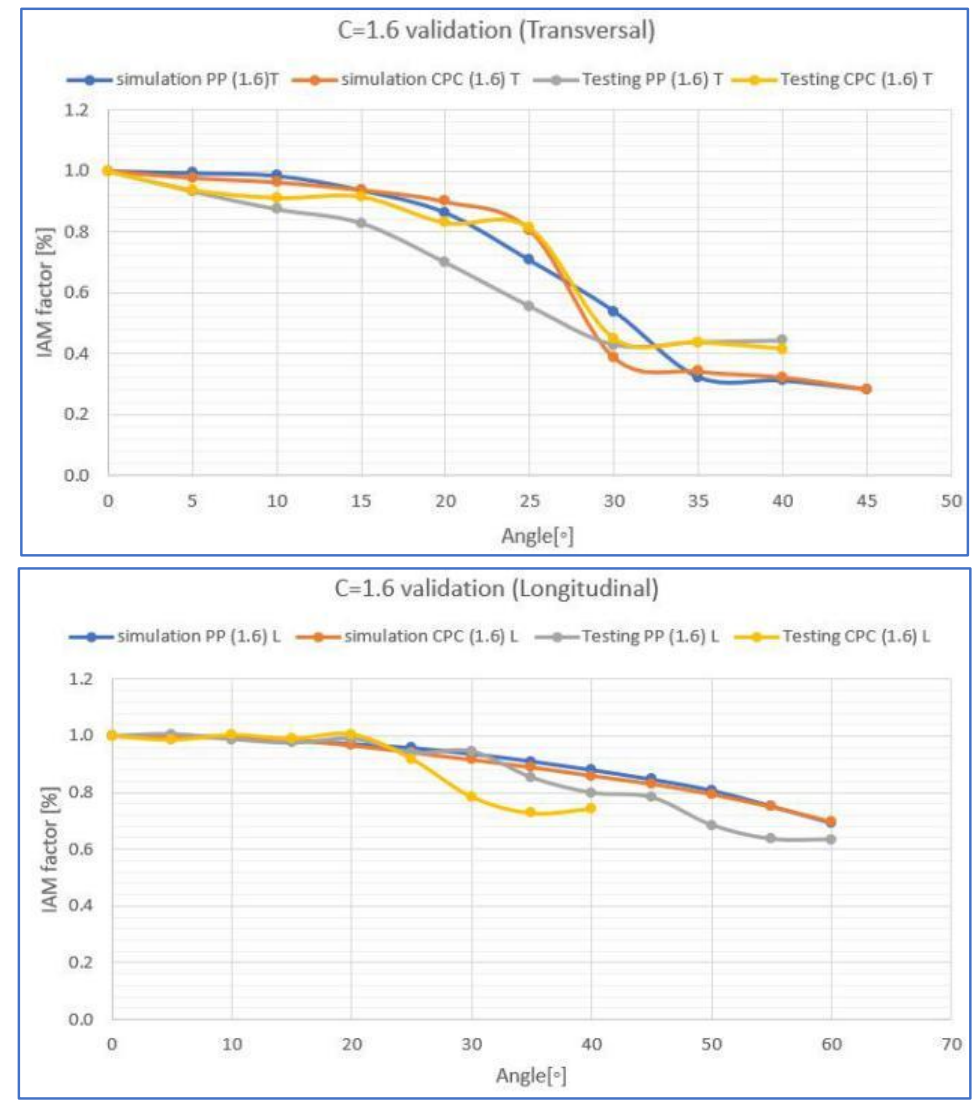

Fig. 13: Longitudinal (bottom) and Transversal (top) IAMs simulation result with $\mathrm{C}=1.6$.

For the longitudinal IAM of both the PP and the CPC with $\mathrm{C}=1.6$, there is a perfect match until $25^{\circ}$. The PP has a perfect match until $30^{\circ}$. After this point, there is a minor divergence. For the transversal IAM, although the measurement values are slightly inferior the simulated, the shape of the curves are similar. This happens for both $\mathrm{PP}$ and CPC.

\subsection{Current-Voltage Curve (IV)}

An IV curve was performed detailing the collector electrical performance. This curve was performed at solar noon with the collector at best tilt (normal to the collector). 


\subsubsection{PP Collector Current-Voltage Curve at Peak Power}

The result for PP collector geometry under the two concentration factors are shown in tables below. It can be observed that both IV curves have a very similar shape with only the intensity increasing for the collector with the higher concentration factor.

Tab. 3: IV characteristics for $\mathbf{C}=\mathbf{1 . 2}$

\begin{tabular}{|c|c|c|c|}
\hline & $I_{S C}(\mathrm{~A})$ & $V_{O C}(\mathrm{~V})$ & $P_{\max }(\mathrm{W})$ \\
\hline Panel 1 & 2.67 & 23.57 & 45.60 \\
\hline Panel 2 & 2.75 & 23.42 & 46.80 \\
\hline \multicolumn{3}{|c|}{ Tab. 4: IV characteristics for C= 1.6 } & $P_{\max }(\mathrm{W})$ \\
\hline & $I_{S C}(\mathrm{~A})$ & $V_{O C}(\mathrm{~V})$ & 62.04 \\
\hline Panel 3 & 3.60 & 24.10 & 62.31 \\
\hline
\end{tabular}
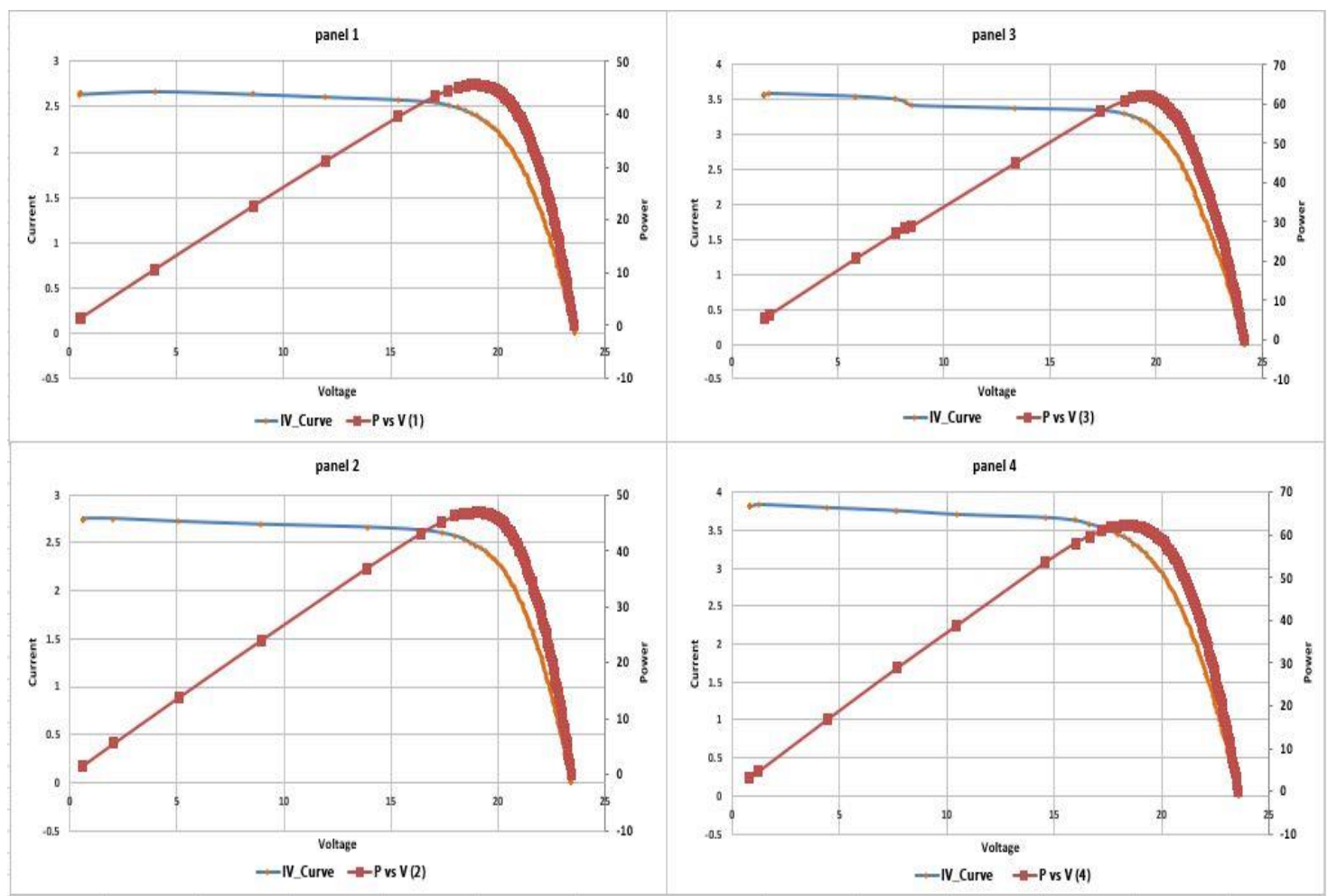

Fig. 14: Current-voltage curves of PP collector.

\subsubsection{CPC collector Current-Voltage Curve at Peak Power}

The IV characteristics are shown in tab. 5 and 6 and comparing with tab. 3 and 4 respectively. The PP collector has a higher peak performance than the CPC for both concentrations.

\begin{tabular}{|c|c|c|c|}
\hline & $I_{s c}(\mathrm{~A})$ & $V_{O C}(\mathrm{~V})$ & $P_{\max }(\mathrm{W})$ \\
\hline Panel 1 & 2.15 & 23.80 & 37.25 \\
\hline Panel 2 & 2.37 & 23.30 & 38.28 \\
\hline \multicolumn{4}{|c|}{ Tab. 6: IV characteristics at $\mathrm{C}=\mathbf{1 . 6 .}$} \\
\hline & $I_{s c}(\mathrm{~A})$ & $V_{o c}(\mathrm{~V})$ & $P_{\max }(\mathrm{W})$ \\
\hline Panel 3 & 3.30 & 24.39 & 58.30 \\
\hline Panel 4 & 3.40 & 24.39 & 60.40 \\
\hline
\end{tabular}




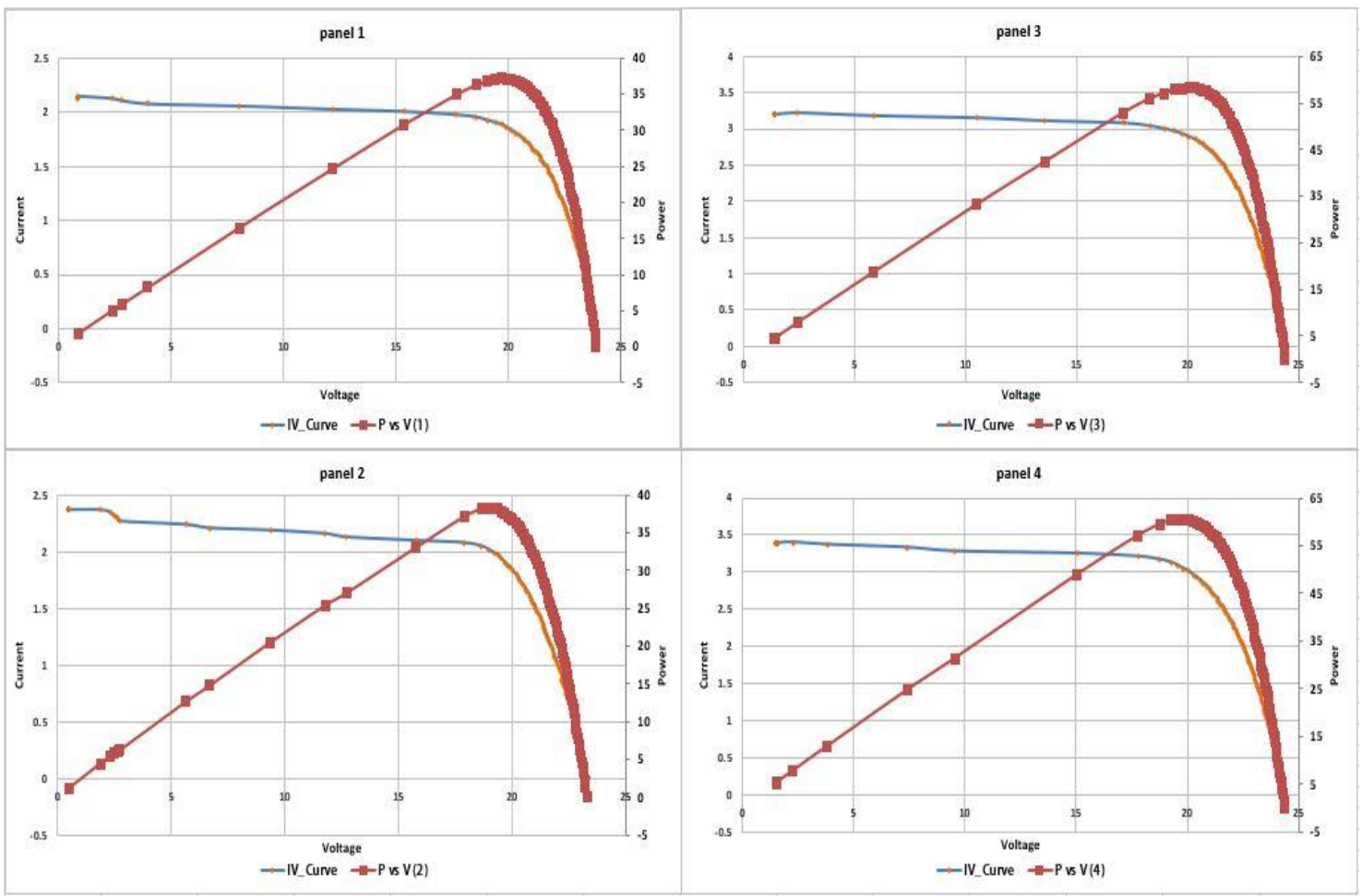

Fig. 15: Current-voltage curves of CPC collector.

\subsection{Simulation of the Annual Energy Received}

Lastly, using Tonatiuh were are able to obtain the total energy received from the sun, assuming that all days of the year are fully sunny, which allows a comparison point. Considering cell efficiency $19.7 \%$, the simulated annual electrical performance is outlined below:

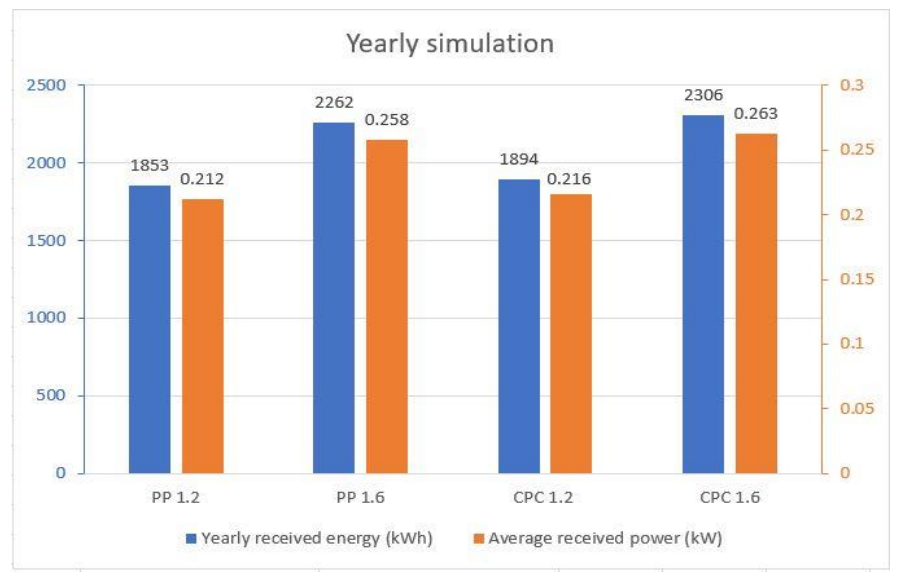

Fig. 16: Simulated annual energy and power yields.

\section{Conclusions}

Two CPVT collectors were simulated, designed, constructed and tested. The collectors were using a PP and CPC reflector geometry with a concentration factor of 1.2 and 1.6.

Outdoor power values (measured at solar noon and best incidence angle) are higher for PP than for CPC. For a concentration of 1.2, PP is $18 \%$ higher and for a concentration of 1.6, PP is $4 \%$ higher. IV curves are as expected for both concentrations, with higher concentrations displaying a higher intensity. 
As for the simulated relative measure of performance, the IAM, longitudinal curves of the PP and CPC closely match for both concentrations. On the transversal, namely for concentration 1.2, the curves are not matching perfectly.

The comparison between simulated and measured values is not straightforward. In the longitudinal IAM of both the $\mathrm{PP}$ and the $\mathrm{CPC}$ with $\mathrm{C}=1.6$, there is a perfect match between measured and simulated until $25^{\circ}$. For the PP the perfect match extends until $30^{\circ}$. After this point, there is a minor divergence. For the transversal IAM, although the measurement values are slightly inferior the simulated, the shape of the curves are similar. This happens for both PP and CPC.

\section{Acknowledgments}

This project has received funding from the European Union's Horizon 2020 research and innovation program

mme under grant agreement No. 814865 (RES4BUILD). This output reflects only the author's view and the European Union cannot be held responsible for any use that may be made of the information contained therein.

\section{References}

IRENA, 2017. Renewable power generation costs in 2017. IRENA, p. 160.

M. I., Al-Najideen, S. S., Alrwashdeh, 2017. Design of a solar photovoltaic system to cover the electricity demand for the faculty of Engineering - Mu'tah University in Jordan. Resource-Efficient Technologies, vol. 3, no. 4 , pp. $440-445$.

Jafrancesco, D., Sani, E., Fontani, D., Mercatelli, L., San- soni, P., Giannini, A., Francini, F., 2012. Simple methods to approximate CPC shape to preserve collection efficiency. International Journal of Photoenergy, 863654(7).

Nilsson, J., 2005. Optical Design and Characterization of Solar Concentrators for Photovoltaics. PhD thesis. Lund University.

Sharaf O., Orhan M., 2105. Concentrated photovoltaic thermal (CPVT) solar collector systems: Part1 Fundamentals, design considerations and current technologies. Renewable and Sustainable Energy Reviews, $50,1500-1565$.

Kramer, K., Helmers, H., 2013. The interaction of standards and innovation: Hybrid photovoltaic-thermal collectors. Solar Energy, 98, 434-439.

Good, C., 2016. Environmental impact assessments of hybrid photovoltaic thermal (PV/T) systems - A review. Renewable and Sustainable Energy Reviews, 55, 234-239.

Blanco, M., Mutuberria, A., Garcia, P., Gastesi, R., Martin, V., 2009. Preliminary validation of Tonatiuh. In SolarPACES, Conf. Proceedings.

Duffie J., Beckman W., 2013. Solar engineering of thermal processes. John Wiley and Sons.

W.B., Stine, R.W. Harrigan, 1986. Solar Energy Systems Design. John Wiley and Sons, 1986.

Adsten, M., Helgesson, A., Karlsson, B., 2005. Evaluation of CPC - collector designs for stand-alone, roof or wall installation. Solar Energy, 79.6, 638-647. 